\title{
ERCC1, defective mismatch repair status as predictive biomarkers of survival for stage III colon cancer patients receiving oxaliplatin- based adjuvant chemotherapy
}

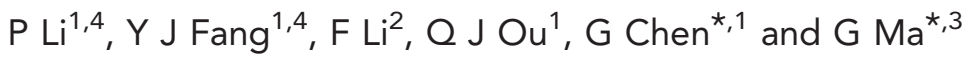

${ }^{1}$ Department of Colorectal Surgery, State Key Laboratory of Oncology in South China, Sun Yat-sen University Cancer Center, Guangzhou, China; ${ }^{2}$ Department of Occupational and Environmental Health School of Public Health, Tongji Medical College, Huazhong University of Science and Technology, Wuhan, China and ${ }^{3}$ Department of Intensive Care Unit (ICU), State Key Laboratory of Oncology in South China, Sun Yat-sen university Cancer Center, Guangzhou, China

Background: Excision repair cross-complementation group 1 (ERCC1) expression status has been identified as a candidate marker for predicting efficacy of oxaliplatin (OX) treatment for metastatic colorectal cancer (CRC) in several trials. Also, an association between expression of mismatch repair (MMR) genes and favourable postoperative survival in stage II CRC receiving 5-FU chemotherapy has been identified. It is unknown if the expression of ERCC1 protein and MMR status are associated with survival of stage III colon cancer receiving OX-based chemotherapy.

Methods: Immunohistochemistry $(\mathrm{IHC})$ analysis of the expression of MMR and ERCC1 was performed on tumour tissue of 255 patients with stage III colon cancer. In all, 95 patients received fluoropyrimidine-based chemotherapy and 160 patients received OX-based chemotherapy. A predictive model for 5-year disease-free survival (DFS) and overall survival (OS) was constructed using Kaplan-Meier analysis, logistic and Cox regression.

Results: Patients who were treated with OX-based therapy with positive ERCC1 tumours had lower 5-year DFS (54\%) and OS (60\%) than those with negative ERCC1 tumours (72\% and 78\%, respectively; DFS HR: 1.98, 95\% confidence interval (Cl): 1.19-3.31, $P=0.009$; OS HR: 2.44, 95\% Cl: 1.37-4.34, $P=0.02$ ). Excision repair cross-complementation group 1 status did not impact DFS or OS in fluorouracil group (DFS HR: 1.16, 95\% Cl: 0.63-2.14, $P=0.62$; OS HR: 1.16, 95\% Cl: 0.63-2.14, $P=0.63$ ), whereas MMR status had no impact on DFS or OS in either group.

Conclusion: Excision repair cross-complementation group 1 status is highly predictive of which patients will benefit from the addition of OX to 5-FU for stage III colon cancer. Mismatch repair status had no predictive value in this setting.

Oxaliplatin (OX)-based chemotherapy has been the standard adjuvant treatment for stage III colon cancer patients since 2004, when the MOSAIC trial demonstrated a 3-year disease-free survival (DFS) improvement of FOLFOX4 compared with infusional fluorouracil and leucovorin (Andre et al, 2004). These results were supported by subsequent trials (NSABP C-07, NO16968; Kuebler et al, 2007; Haller et al, 2011).

However, a recent update of the MOSAIC trial suggests that with further follow-up, the benefit of OX is not of the magnitude that was expected, particularly in elderly patients (Mayer, 2012).

\footnotetext{
*Correspondence: Dr G Chen; Email: violet.lipan@163.com or Dr G Ma; Email: magang@sysucc.org.cn
}

${ }^{4}$ These authors contributed equally to this work.

Received 12 November 2012; revised 23 January 2013; accepted 30 January 2013; published online 12 March 2013

(c) 2013 Cancer Research UK. All rights reserved 0007-0920/13 
This has particular relevance because of the consequences that many patients who receive OX encounter a cumulative doserelated peripheral neuropathy that persists in a subset of patients and that can impact on the quality of life.

Oxaliplatin is a third-generation 1,2-diaminocyclohexane platinum analogue with demonstrated preclinical and clinical activity (Scheeff et al, 1999; Vaisman et al, 1999). In vitro studies have shown that 1,2-diaminocyclohexane-containing platinum compounds belong to a distinct group of cytotoxic compounds with different mechanisms of action and resistance than cisplatin and carboplatin (Giacchetti et al, 2000; Sharp et al, 2002). These adducts are recognised and repaired by the nucleotide excision repair pathway, which is a major cellular defence mechanism against the cytotoxic effects of platinum-based chemotherapeutic agent. Nucleotide excision repair pathway involves a number of genes, including excision repair cross-complementation group 1 (ERCC1). This protein forms a heterodimer with xeroderma pigmentosum group $\mathrm{F}$ to execute the incision into the DNA strand (Raymond et al, 2002; Goodisman et al, 2006; Gossage and Madhusudan, 2007; Rabik and Dolan, 2007; Martin et al, 2008). Based on the results of The International Adjuvant Lung Cancer Trial Collaborative Group (IALT) trial (Arriagada et al, 2004), ERCC1 is considered a possible predictive biomarker for cisplatin use in NSCLC. Its predictive value for OX is still unclear.

One of the genetic pathways involved in colorectal cancer (CRC) is deficient mismatch repairing (MMR). Mismatch repair defects are produced by germline mutations in any of the genes: MLH1, MSH2, MSH6 and PMS2. Another frequent microsatellite instability (MSI) mechanism is by hypermethylation of MLH1 promoter in MSI sporadic cases (Benatti et al, 2005; Bertagnolli et al, 2009; Tesniere et al, 2010; Sinicrope et al, 2011). Stage II patients with MSI-H have a better prognosis and may actually be harmed by 5 -FU treatment. However, the predictive impact of MMR status in patients with stage III colon cancer treated with adjuvant 5-FU-OX combination chemotherapy has rarely been explored (Zaanan et al, 2010, 2011). Many studies have shown ERCC1 and MMR status have closely correlation with OX. But most studies were based on the combination of 5-FU and OX, other researches about the prediction of biomarkers on OX were carried in vitro(Lurje et al, 2007; Avraam et al, 2011), and most trials were limited to advanced CRC (Shirota et al, 2001; Stoehlmacher et al, 2004; Viguier et al, 2005; Ruzzo et al, 2007; Balin-Gauthier et al, 2008).

Because of the evolving standard, a prospective evaluation of the predictive effect of ERCC1 or MMR status on fluorouracil or OX-based chemotherapies is quite difficult. We took advantage of the practice patterns before 2003 and after to analyse the predictive effect of ERCC1 and MMR status on OX-based adjuvant chemotherapy.

\section{MATERIALS AND METHODS}

Patients. The ethic committee of Sun Yat-sen University Cancer Center approved this retrospective study. This retrospective study included 255 histologically confirmed stage III colon cancer patients with available tumour specimens who received curative surgical resection followed by adjuvant mFOLFOX6/XELOX/Mayo clinic chemotherapy from January 2000 to December 2008. For all patients, chemotherapy started at the Sun Yat-sen University Cancer Center within 8 weeks after surgery, where follow-up was further conducted. Patients whose treatment started before June 2003 received Mayo clinic regimen $(n=95)$, whereas those treated after October 2003 were given mFOLFOX6 or XELOX chemotherapy $(n=160)$. Exclusion criteria were age less than 18 years and older than 85 years, rectal cancer, and abdominopelvic radiotherapy, severe complication, changing regimen, multiprimary cancer, family history (first-degree and second-degree relatives had any kind of cancer), familial adenomatous polyposis.

The combined treatment group received mFOLFOX6/XELOX regimen treatment, the single-drug group used Mayo Clinic regimen. Immunohistochemistry analysis of the expression of MMR and ERCC1 was performed on tumour tissue of the stage III colon cancer. A predictive model for DFS and overall survival (OS) was constructed using Kaplan-Meier analysis, logistic and Cox regression.

Treatment and follow-up. The combined treatment group received mFOLFOX6 (OX $85 \mathrm{mg} \mathrm{m}^{-2}$ infused for $2 \mathrm{~h}$, day 1 ; CF $200 \mathrm{mg} \mathrm{m}^{-2}$, i.v., $2 \mathrm{~h}$, day 1; 5-FU $400 \mathrm{mg} \mathrm{m}^{-2}$, iv, then continuous infusion of $2400 \mathrm{mg} \mathrm{m}^{-2}$ for $46 \mathrm{~h}$, day $1-2$, $\mathrm{q} 2 \mathrm{w} \times 12$ )/XELOX (OX $130 \mathrm{mg} \mathrm{m}^{-2}$ infused for $2 \mathrm{~h}$, day 1 ; Xeloda $2000 \mathrm{mg} \mathrm{m}^{-2}$, po, $1-14$ days, $\left.\mathrm{q} 3 \mathrm{w} \times 8\right)$ regimen treatment, the single-drug group used Mayo Clinic regimen $\left(5-\mathrm{FU} 425 \mathrm{mg} \mathrm{m}^{-2}\right.$, i.v., CF $200 \mathrm{mg} \mathrm{m}^{-2}$, i.v., $1-5$ days, $\mathrm{q} 4 \mathrm{w} \times 6$ ). After surgery, tumour recurrence was detected by physical examination, serum carcinoembryonic antigen (CEA) assay, and abdominal and thoracic imaging every 3-6 months for 3 years, every 6 months for the following 2 years, then annually. The duration of follow-up was defined as the time between surgery and disease recurrence, death or last hospital contact (scheduled follow-up or telephone contact). The cutoff date for this analysis was March 2011. At the end of follow-up, $64(40 \%)$ patients in the combined treatment group had relapse or metastasis, as compared with $45(47.4 \%)$ in the single-drug group. In all, $54(33.8 \%)$ patients in the combined treatment group had died, as compared with 45 (47.4\%) in the single-drug group. The mean follow-up was 63 and 76 months for the combined and single-drug treatment groups, respectively (median 68 and 86 months, respectively).

IHC analysis. The paraffin tissue blocks were stored at room temperature. Blocks of formalin-fixed, paraffin-embedded adenocarcinoma tissue comprising an area of normal colonic mucosa adjacent to the tumour were selected in each case. Sections of $4 \mathrm{~mm}$ from the paraffin-embedded tissue samples were cut into silanetreated Super Frost slides and left to dry at $37^{\circ} \mathrm{C}$ overnight. The slides were deparaffinised in xylene and rehydrated in pure ethanol. Endogenous peroxidase was blocked using 3\% hydrogen peroxide in methanol for $30 \mathrm{~min}$. Before immunostaining, antigen retrieval was done by immersing sections in citrate buffer (MMR: $\mathrm{pH}$ 8.0, ERCC1: PH 9.0). Sections were then incubated for $15 \mathrm{~min}$ at room temperature with antibodies to ERCC1 (dilution 1/100 clone 8 F1; Abcam, Beijing, China), MLH1 (dilution 1/100 clone G168-728; Pharmingen, Shanghai, China), MSH2 (dilution 1/100 clone FE11; Calbiochem, Shanghai, China). The intensity of immunostaining for ERCC1/MLH1/MSH2 was reviewed and scored according to the location of cytoplasmic with or without positive nucleus. The proportion of cells with ERCC1 expression was rated as follows (Olaussen et al, 2006): 0 points, $<5 \%$ positive tumour cells; 1 point, $5-25 \%$ positive cells; 2 points, $26-50 \%$ positive cells; 3 points, $51-75 \%$ positive cells; and 4 points, $>75 \%$ positive cells, and the intensity of staining varied from weak to strong. The intensity was classified as a scale of 0 (no staining), 1 (weak staining, light yellow), 2 (moderate staining, yellowish brown) and 3 (strong staining, brown). The specimens were attributed to two groups, according to their overall score: $0-1$ point, ERCC1 negative; $\geqslant 2$ points, ERCC1 positive.

The proportion of cells with MLH1 and MSH2 expression was rated as follows: 0 points, no positive tumour cells; 1 point, $<10 \%$ positive tumour cells; 2 points, $11-50 \%$ positive cells; 3 points, $51-80 \%$ positive cells; and 4 points, $>80 \%$ positive cells, and the intensity of staining varied from weak to strong. The intensity was classified as a scale of 0 (no staining), 1 (weak staining, light yellow), 2 (moderate staining, yellowish brown) and 3 (strong 

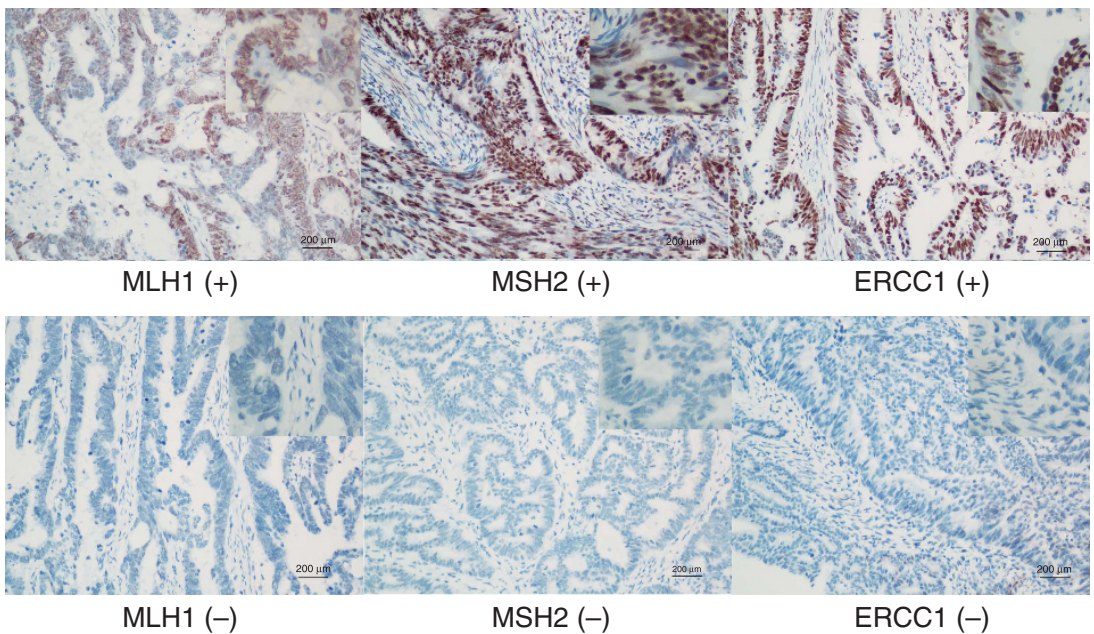

Figure 1. Illustrative immunostainings. Positive (upper panel) and negative (lower panel) for MLH1, MSH2 and ERCC1.

staining, brown). The specimens were attributed to two groups, according to their multiplication score: $0-1$ point, MLH1/MSH2 negative; $\geqslant 2$ points, MLH1/MSH2 positive. The score system was routinely used by the department of pathology in the Sun Yat-sen University Cancer Center for patients' diagnosis. The MSI phenotype was defined as the complete lack of MLH1 and MSH2 expression by IHC (Zaanan et al, 2010). Whole tissue sections were read separately by two pathologists blinded to the patients' clinical characteristics. Discordant cases were reviewed by a supplementary pathologist to reach a consensus. Illustrative immunostainings were showed in Figure 1.

Statistical analysis. Data were described as frequencies (percentages) or means and medians (range). Differences in distributions between the variables examined were assessed with the $\chi^{2}$ or the Fisher's exact test. The primary end point was DFS, defined as the time between the date of surgery and the first event (local or distant disease recurrence). Patients who were alive and relapse free at the last contact were censored at the last follow-up date. Overall survival was defined as the time elapsed from the date of surgery until tumour-induced death. Surviving patients were censored on the last follow-up date. Median follow-up and the 95\% confidence interval (CI) were calculated using the reverse Kaplan-Meier method. Survival curve was estimated with the Kaplan-Meier method and compared using the log-rank test. The DFS and OS rate at 5 years was reported according to ERCC1 and MMR status with its 95\% CI. Disease-free survival and OS curves of the groups of patients receiving Mayo Clinic or mFOLFOX6/XELOX were compared according to the tumour MSI phenotype and ERCC1 expression. A multivariate Cox model was constructed. Multivariate Cox analysis included all relevant clinical variables, whatever their univariate Cox $P$-value, namely, age, sex, differentiation grade, CEA level, ERCC1 expression, MMR status. Two-sided $P$-values of less than 0.05 were considered statistically significant.

\section{RESULTS}

The demographic characteristics of the 225 patients (144 males and 111 females) with stage III colon cancer were given in Table 1. Their median age at diagnosis was 55 years (ranged 26-83 years), the 5 -year DFS and OS were $59 \%$ and $65 \%$, respectively.

Expression of ERCC1 and MMR status. In combined group, 72 cases (45\%) had negative ERCC1 tumour and 88 cases $(55 \%)$ had positive tumour, 43 cases (45.3\%) had negative ERCC1 tumour and 52 cases $(54.7 \%)$ had positive tumour in the single-drug group, with no difference between them $(P=0.66)$.

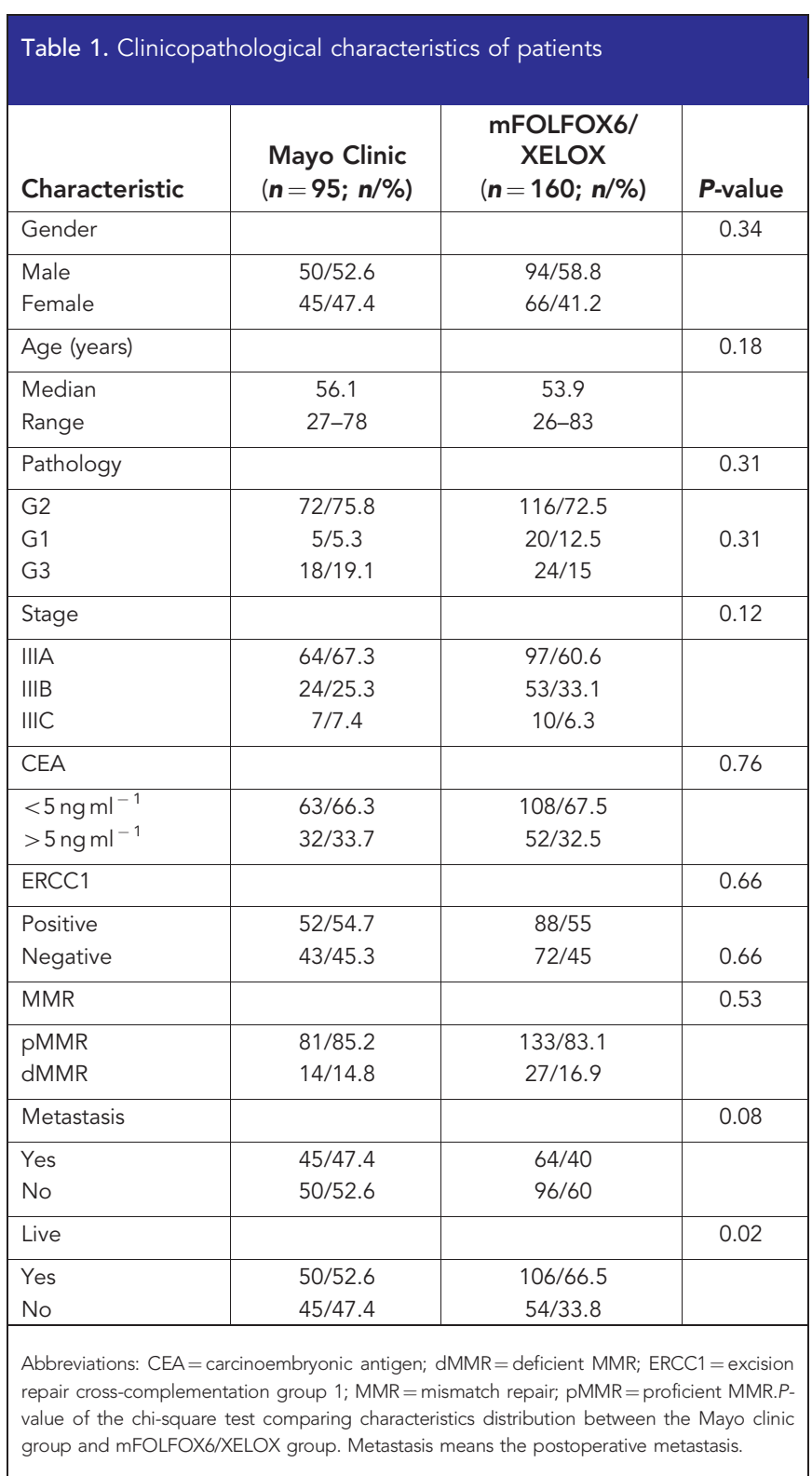

In all, 27 cases (16.9\%) with dMMR tumour and 133 cases (83.1\%) showed proficient MMR (pMMR) status in the combined treatment group, 14 cases (14.8\%) with dMMR tumour and 

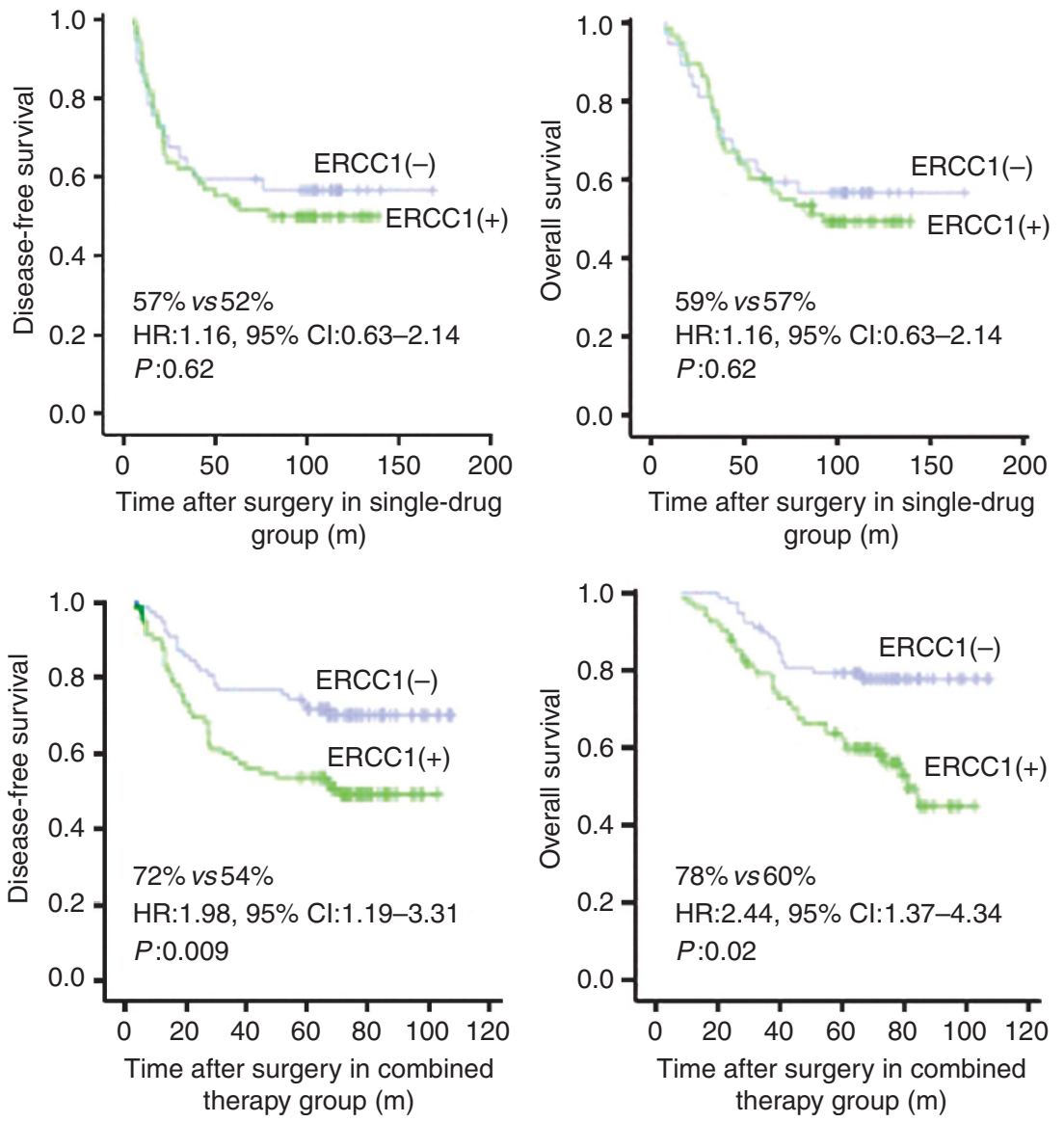

Figure 2. DFS and OS according to the expression of ERCC1 and treatment.

81 cases $(85.2 \%)$ showed pMMR status in the single-drug group, MMR status had no significant difference between these two groups $(P=0.53)$.

ERCC1 expression and MMR status in stage III colon cancer with clinicopathological parameters are shown in Table 1.

Benefit of OX-based chemotherapy. The 5-year DFS of patients treated by mFOLFOX6/XELOX and Mayo Clinic regimen was $62 \%$ and 55\%, respectively (HR: 7.1; 95\% CI: 4.46-11.31; $P<0.001$ ). The 5 -year OS rate between combined therapy and the single-drug group was $69 \%$ and $58 \%$, respectively (HR: $7.4 ; 95 \%$ CI: $4.67-11.74$; $P<0.001$ ), confirming that adding OX to a regimen of FL improves the adjuvant treatment of colon cancer.

Relationship between ERCC1 expression and survival. The 5 -year DFS was significantly higher in combined therapy group with negative ERCC1 tumours (72\%) than in the same group patients with positive ERCC1 tumours (54\%, HR: 1.98; 95\% CI: $1.19-3.31 ; P=0.009)$. The OS was also higher in combined therapy group with negative ERCC1 tumours (78\%) than in the same group patients with positive ERCC1 tumours (60\%, HR: 2.44; 95\% CI: $1.37-4.34 ; P=0.02)$. The protein expression of ERCC1 showed no statistic significance of DFS or OS in fluorouracil group (DFS 57\% vs 52\%, HR: $1.16,95 \%$ CI: $0.63-2.14, P=0.62$; OS $59 \%$ vs 57\%, HR: $1.16,95 \%$ CI: $0.63-2.14, P=0.63)$. The survival plots of ERCC1 expression are shown in Figure 2.

Relationship between MMR status and survival. The 5-year DFS had no difference in combined therapy group with dMMR tumours $(73 \%)$ between in the same group patients with pMMR tumours (61\%, HR: $1.68,95 \%$ CI: $0.76-3.68, P=0.19)$. Overall survival also did not show difference between dMMR tumours (78\%) and pMMR tumours in combined therapy group (67\%, HR:
1.37, 95\% CI: $0.62-3.03, P=0.44)$. The MMR status showed no statistic significance of DFS or OS in fluorouracil group (DFS 63\% vs 53\%, HR: $1.66,95 \%$ CI: $0.70-3.92, P=0.25$; OS $64 \%$ vs $57 \%$, HR: 1.67, 95\% CI: $0.71-3.96, P=0.24)$. The survival plots of MMR status are shown in Figure 3.

Multivariate analyses of survival. Age, sex, pathology, tumour stage, CEA level and ERCC1 showed statistic difference in univariate Cox analysis $(P<0.05)$. Age was continuous variable. Sex, pathology, tumour stage, CEA level and ERCC1 were dichotomous variables as shown in Table 1. Among the variables analysed in the mulivariate Cox model (age, sex, pathology, tumour stage, CEA, ERCC1), tumour stage (stage IIIA/B vs IIIC: HR: 2.03; 95\% CI: $1.05-2.72 ; P<0.001$ ), age (HR: 0.98; 95\% CI: 0.96-0.99; $P=0.008$ ) and CEA level (HR: $1.52 ; 95 \%$ CI: $1.24-1.87 ; P<0.001$ ) were significantly associated with DFS. In multivariate analysis, ERCC1 expression remained an independent significant predictive factor for DFS and OS in combined therapy group (DFS HR: $1.79,95 \%$ CI: $1.21-2.67, P=0.004$; OS HR: $1.85,95 \%$ CI: $1.37-2.51, P=0.002)$. The multi-analysis results are shown in Tables 2 and 3.

\section{DISCUSSION}

Standard chemotherapy regimens are often developed based on data generated among large populations of patients with the tacit acknowledgement that some patients benefit and others do not. Such is the case with OX-based chemotherapy for stage III colon cancer patients. This means that a subset of patients will suffer long-term toxicity (neuropathy) from a treatment that may not have conferred a benefit otherwise. In an effort to determine 

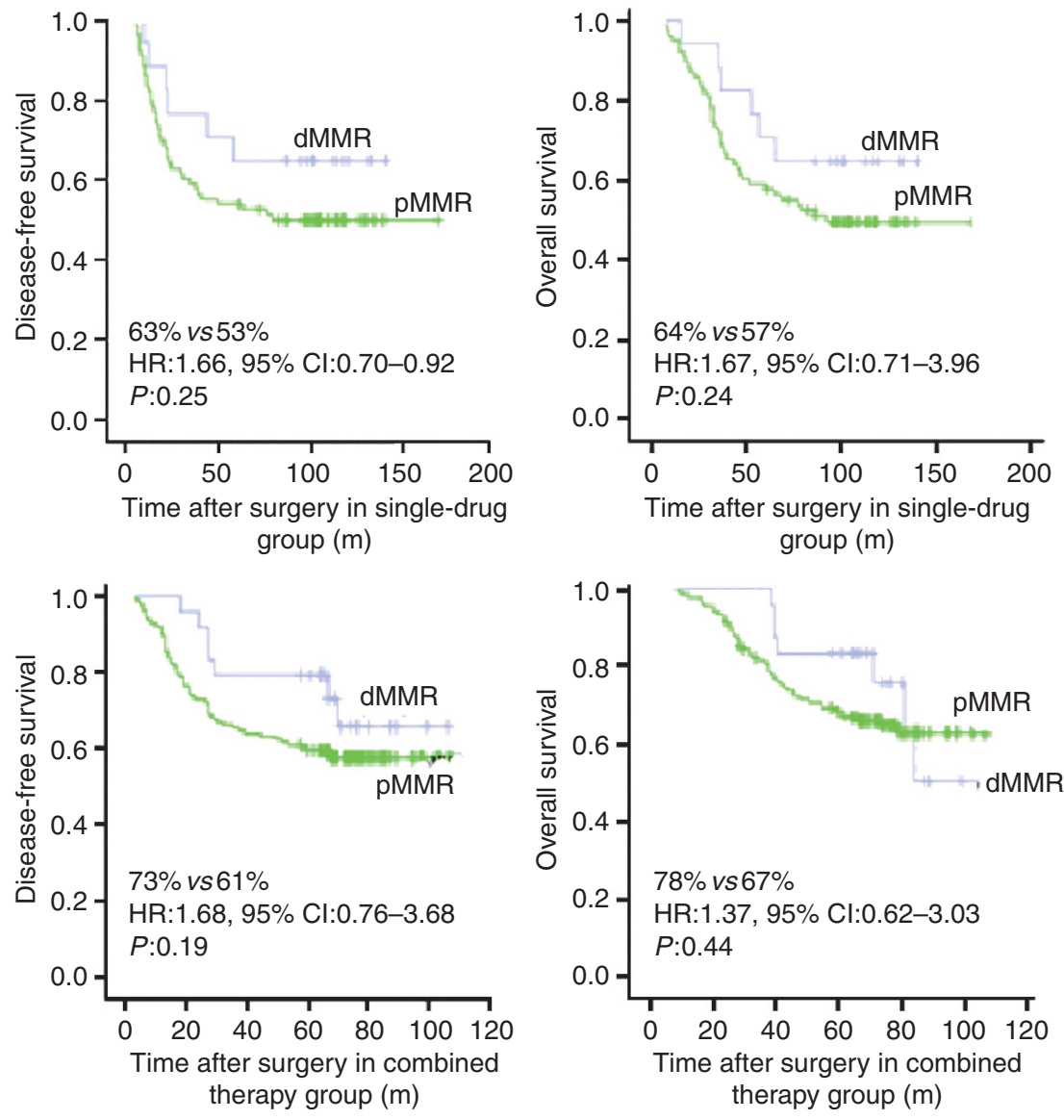

Figure 3. DFS and OS according to MMR status and treatment.

\begin{tabular}{|c|c|c|c|c|}
\hline & \multicolumn{4}{|c|}{$95 \% \mathrm{Cl}$} \\
\hline Variable & HR & Lower & Upper & $\boldsymbol{P}$-value \\
\hline Gender & 1.070 & 0.725 & 1.580 & 0.733 \\
\hline Age & 0.979 & 0.964 & 0.994 & 0.008 \\
\hline Pathology & 1.071 & 0.915 & 1.254 & 0.394 \\
\hline Stage & 2.025 & 1.505 & 2.723 & $<0.001$ \\
\hline CEA & 1.532 & 1.239 & 1.872 & $<0.001$ \\
\hline ERCC1 & 1.793 & 1.205 & 2.668 & 0.004 \\
\hline
\end{tabular}

\begin{tabular}{|c|c|c|c|c|}
\hline & \multicolumn{4}{|c|}{$95 \% \mathrm{Cl}$} \\
\hline Variable & HR & Lower & Upper & $P$-value \\
\hline Gender & 1.134 & 0.752 & 1.709 & 0.550 \\
\hline Age & 0.973 & 0.957 & 0.989 & 0.001 \\
\hline Pathology & 1.066 & 0.901 & 1.262 & 0.454 \\
\hline Stage & 1.854 & 1.854 & 1.367 & $<0.001$ \\
\hline CEA & 1.459 & 1.459 & 1.179 & 0.001 \\
\hline ERCC1 & 1.971 & 1.971 & 1.288 & 0.002 \\
\hline
\end{tabular}

whether there is a biomarker that could potentially be used to enrich the population of patients more likely to benefit from OX-based therapy, we applied the time difference of chemotherapy to analyse the predictive effect of ERCC1 and MMR status on OX-based chemotherapy.

Overexpression of ERCC1 has been reported in cisplatinresistant cancer cell line (Arriagada et al, 2004). Early clinical data suggested that high intratumoral level of ERCC1 mRNA was associated with insensitivity to OX-based therapy in CRC (Shirota et al, 2001). Balin-Gauthier et al (2008) found there was an association between the low expression of ERCC1 gene and the increase of OX-DNA composition in HCT-8 cells, which were very sensitive to OX, but in HCT-116 cells, which were resistant to OX, did not find this change. The polymorphism at codon 118 changed

a common codon usage (AAC) to an infrequent codon (AAT), both coding for asparagine. Interestingly, it has been proposed that this $\mathrm{C}>\mathrm{T}$ substitution impaired ERCC1 translation. In an in vitro study, cells carrying the $\mathrm{T}$ allele showed a poor capacity to repair the adducts induced by cisplatinum. Viguier et al (2005) supported the pharmacogenetic role of the $118 \mathrm{C}>\mathrm{T}$ change and emphasised the results that point to the $\mathrm{T}$ allele as a marker of a better outcome in patients with CRC treated with OX-based schemes. However, Ruzzo et al (2007) and Stoehlmacher et al (2004) suggested that patients with a $\mathrm{C} / \mathrm{C}$ genotype showed the most favourable survival in terms of the ERCC1-118 polymorphism. Thus, the relationship between ERCC1-118 polymorphism and clinical outcome of patients receiving OX-based chemotherapy for advanced CRC remains controversial. 
At present, the evaluation of ERCC1 has been largely limited to advanced patients. Shirota et al (2001) treated the unresectable CRC with FOLFOX regimen after the failure of FOLFIRI therapy and found that ERCC1 mRNA expression level was closely related to the sensitivity of the OX-based scheme $(P<0.01)$. Lenz study found that the advanced CRC with high expression of ERCC1 should not accept OX-based chemotherapy (Grimminger et al, 2012). This research also showed that ERCC1 was a good predictive marker for OX-based treatment used for stage III colon cancer patients, and there was no predictive value of ERCC1 for 5 -FU treatment in this setting group.

Based on the result of many large clinical research (NCCTG GIVIO, ECOG, PETACC-3), NCCN guideline suggested: stage II colon cancer patients planning to accept fluorouracil adjuvant chemotherapy are strongly recommended to take MMR detection. Stage II patients with MSI-H tumour have better prognosis, but cannot benefit from 5-FU chemotherapy. PETACC-3 study found that the expression rate of MSI in stage II, III, ( ) CRC were $22 \%, 12 \%$ and $3.5 \%$, respectively; the prognostic value of MMR was more important than the predictive value for 5-FU treatment; MMR showed predictive value for stage II CRC used 5-FU treatment. However, this phase III trial only compared biweekly infusional fluorouracil/leucovorin alone or with irinotecan in the adjuvant treatment of stage III colon cancer and did not evaluated the predictive value for OX (Van Cutsem et al, 2009).

Clinical and preclinical studies strongly implicated the loss of MMR, in particular the loss of hMLH1, was in resistance to cisplatin (Brown et al, 1997; Watanabe et al, 2001). However, MMR deficiency did not affect the resistance to OX, which formed DNA-adducts that were not recognised by the MMR machinery (Raymond et al, 2002). Nevertheless, the predictive impact of MMR status in patients with stage III colon cancer treated with adjuvant OX-based combination chemotherapy has rarely been explored. Zaanan et al (2011) enrolled 303 stage III colon cancer patients received FOLFOX chemotherapy, 34 cases with dMMR tumour (11.2\%), compared with 269 cases with pMMR tumour (73.8\%), 3-year DFS of dMMR showed great benefit (90.5\% vs $73.8 \%, P=0.027)$. Another study done by Zaanan assigned 233 stage III colon cancer patients into two treatments (FL chemotherapy in 124 cases, FOLFOX chemotherapy in 109 cases), 3-year DFS showed no statistically difference of pMMR patients between these two groups (FL group: $73.6 \%$, FOLFOX group: $80.3 \%, P=0.15$ ). But there was DFS benefit of dMMR patients (FL group: $57.9 \%$, FOLFOX group: $100 \%, P=0.01)$. However, this study involved too little patients with $\mathrm{dMMR}$ tumour and the results were not persuasive (FL groups: 20, FOLFOX groups: 12; Zaanan et al, 2010). Our study showed MMR status had no relevant predictive value for OX or 5-FU used for stage III colon cancer patients and still had the same sample problem (mFOLFOX6/XELOX: 27 cases, Mayo Clinic: 14 cases) with the above-mentioned studies. There were many speculations for the result: DNA-adducts structure of OX cannot be recognised by the MMR machinery. As mentioned above, the portion of dMMR status in stage III was lower than in stage II colon cancer, which may weak the predictive value of MMR. At the same time, the number of cases was too little and cannot draw reliable results.

\section{CONCLUSION}

Our results indicate that ERCC1 status is highly predictive of which patients will benefit from the addition of OX to 5-FU for stage III colon cancer. Mismatch repair status has no predictive value in this setting. Although the IHC test of ERCC1 and MMR status should be considered with caution, our results may have implications for rational development of more effective, lower toxicity and individualised regimens for stage III colon cancer.

\section{ACKNOWLEDGEMENTS}

The study was supported by 'Fundamental Research Funds for The Central Universities' (No 12ykpy55) to Dr G Chen.

\section{REFERENCES}

Andre T, Boni C, Mounedji-Boudiaf L, Navarro M, Tabernero J, Hickish T, Topham C, Zaninelli M, Clingan P, Bridgewater J, Tabah-Fisch I, de Gramont A (2004) Oxaliplatin, fluorouracil, and leucovorin as adjuvant treatment for colon cancer. N Engl J Med 350: 2343-23451.

Arriagada R, Bergman B, Dunant A, Le Chevalier T, Pignon JP, Vansteenkiste J (2004) Cisplatin-based adjuvant chemotherapy in patients with completely resected non-small-cell lung cancer. N Engl J Med 350: 351-360.

Avraam K, Pavlakis K, Papadimitriou C, Vrekoussis T, Panoskaltsis T, Messini I, Patsouris E (2011) The prognostic and predictive value of ERCC-1, p53, bcl-2 and bax in epithelial ovarian cancer. Eur J Gynaecol Oncol 32: 516-520.

Balin-Gauthier D, Delord JP, Pillaire MJ, Rochaix P, Hoffman JS, Bugat R, Cazaux C, Canal P, Allal BC (2008) Cetuximab potentiates oxaliplatin cytotoxic effect through a defect in NER and DNA replication initiation. Br J Cancer 98: 120-128.

Benatti P, Gafa R, Barana D, Marino M, Scarselli A, Pedroni M, Maestri I, Guerzoni L, Roncucci L, Menigatti M, Roncari B, Maffei S, Rossi G, Ponti G, Santini A, Losi L, Di Gregorio C, Oliani C, Ponz DLM, Lanza G (2005) Microsatellite instability and colorectal cancer prognosis. Clin Cancer Res 11: $8332-8340$.

Bertagnolli MM, Niedzwiecki D, Compton CC, Hahn HP, Hall M, Damas B, Jewell SD, Mayer RJ, Goldberg RM, Saltz LB, Warren RS, Redston M (2009) Microsatellite instability predicts improved response to adjuvant therapy with irinotecan, fluorouracil, and leucovorin in stage III colon cancer: Cancer and Leukemia Group B Protocol 89803. J Clin Oncol 27: 1814-1821.

Brown R, Hirst GL, Gallagher WM, McIlwrath AJ, Margison GP, van der Zee AG, Anthoney DA (1997) hMLH1 expression and cellular responses of ovarian tumour cells to treatment with cytotoxic anticancer agents. Oncogene 15: 45-52.

Giacchetti S, Perpoint B, Zidani R, Le Bail N, Faggiuolo R, Focan C, Chollet P, Llory JF, Letourneau Y, Coudert B, Bertheaut-Cvitkovic F, LarregainFournier D, Le Rol A, Walter S, Adam R, Misset JL, Levi F (2000) Phase III multicenter randomized trial of oxaliplatin added to chronomodulated fluorouracil-leucovorin as first-line treatment of metastatic colorectal cancer. J Clin Oncol 18: 136-147.

Goodisman J, Hagrman D, Tacka KA, Souid AK (2006) Analysis of cytotoxicities of platinum compounds. Cancer Chemother Pharmacol 57: $257-267$.

Gossage L, Madhusudan S (2007) Current status of excision repair cross complementing-group 1 (ERCC1) in cancer. Cancer Treat Rev 33: 565-577.

Grimminger PP, Shi M, Barrett C, Lebwohl D, Danenberg KD, Brabender J, Vigen CL, Danenberg PV, Winder T, Lenz HJ (2012) TS and ERCC-1 mRNA expressions and clinical outcome in patients with metastatic colon cancer in CONFIRM-1 and -2 clinical trials. Pharmacogenomics J 12: 404-411.

Haller DG, Tabernero J, Maroun J, de Braud F, Price T, Van Cutsem E, Hill M, Gilberg F, Rittweger K, Schmoll HJ (2011) Capecitabine plus oxaliplatin compared with fluorouracil and folinic acid as adjuvant therapy for stage III colon cancer. J Clin Oncol 29: 1465-1471.

Kuebler JP, Wieand HS, O'Connell MJ, Smith RE, Colangelo LH, Yothers G, Petrelli NJ, Findlay MP, Seay TE, Atkins JN, Zapas JL, Goodwin JW, Fehrenbacher L, Ramanathan RK, Conley BA, Flynn PJ, Soori G, Colman LK, Levine EA, Lanier KS, Wolmark N (2007) Oxaliplatin combined with weekly bolus fluorouracil and leucovorin as surgical adjuvant chemotherapy for stage II and III colon cancer: results from NSABP C-07. J Clin Oncol 25: 2198-2204.

Lurje G, Zhang W, Lenz HJ (2007) Molecular prognostic markers in locally advanced colon cancer. Clin Colorectal Cancer 6: 683-690. 
Martin LP, Hamilton TC, Schilder RJ (2008) Platinum resistance: the role of DNA repair pathways. Clin Cancer Res 14: 1291-1295.

Mayer RJ (2012) Oxaliplatin as part of adjuvant therapy for colon cancer: more complicated than once thought. J Clin Oncol 30: 3325-3327.

Olaussen KA, Dunant A, Fouret P, Brambilla E, Andre F, Haddad V, Taranchon E, Filipits M, Pirker R, Popper HH, Stahel R, Sabatier L, Pignon JP, Tursz T, Le Chevalier T, Soria JC (2006) DNA repair by ERCC1 in non-small-cell lung cancer and cisplatin-based adjuvant chemotherapy. N Engl J Med 355: 983-991.

Rabik CA, Dolan ME (2007) Molecular mechanisms of resistance and toxicity associated with platinating agents. Cancer Treat Rev 33: 9-23.

Raymond E, Faivre S, Chaney S, Woynarowski J, Cvitkovic E (2002) Cellular and molecular pharmacology of oxaliplatin. Mol Cancer Ther 1: 227-235.

Ruzzo A, Graziano F, Loupakis F, Rulli E, Canestrari E, Santini D, Catalano V Ficarelli R, Maltese P, Bisonni R, Masi G, Schiavon G, Giordani P, Giustini L, Falcone A, Tonini G, Silva R, Mattioli R, Floriani I, Magnani M (2007) Pharmacogenetic profiling in patients with advanced colorectal cancer treated with first-line FOLFOX-4 chemotherapy. J Clin Oncol 25: $1247-1254$.

Scheeff ED, Briggs JM, Howell SB (1999) Molecular modeling of the intrastrand guanine-guanine DNA adducts produced by cisplatin and oxaliplatin. Mol Pharmacol 56: 633-643.

Sharp SY, O'Neill CF, Rogers P, Boxall FE, Kelland LR (2002) Retention of activity by the new generation platinum agent AMD0473 in four human tumour cell lines possessing acquired resistance to oxaliplatin. Eur $J$ Cancer 38: 2309-2315.

Shirota Y, Stoehlmacher J, Brabender J, Xiong YP, Uetake H, Danenberg KD, Groshen S, Tsao-Wei DD, Danenberg PV, Lenz HJ (2001) ERCC1 and thymidylate synthase mRNA levels predict survival for colorectal cancer patients receiving combination oxaliplatin and fluorouracil chemotherapy. J Clin Oncol 19: 4298-4304.

Sinicrope FA, Foster NR, Thibodeau SN, Marsoni S, Monges G, Labianca R, Kim GP, Yothers G, Allegra C, Moore MJ, Gallinger S, Sargent DJ (2011) DNA mismatch repair status and colon cancer recurrence and survival in clinical trials of 5-fluorouracil-based adjuvant therapy. J Natl Cancer Inst 103: 863-875.

Stoehlmacher J, Park DJ, Zhang W, Yang D, Groshen S, Zahedy S, Lenz HJ (2004) A multivariate analysis of genomic polymorphisms: prediction of clinical outcome to 5-FU/oxaliplatin combination chemotherapy in refractory colorectal cancer. Br J Cancer 91: 344-354.
Tesniere A, Schlemmer F, Boige V, Kepp O, Martins I, Ghiringhelli F, Aymeric L, Michaud M, Apetoh L, Barault L, Mendiboure J, Pignon JP, Jooste V, van Endert P, Ducreux M, Zitvogel L, Piard F, Kroemer G (2010) Immunogenic death of colon cancer cells treated with oxaliplatin. Oncogene 29: 482-491.

Vaisman A, Lim SE, Patrick SM, Copeland WC, Hinkle DC, Turchi JJ, Chaney SG (1999) Effect of DNA polymerases and high mobility group protein 1 on the carrier ligand specificity for translesion synthesis past platinumDNA adducts. Biochemistry-Us 38: 11026-11039.

Van Cutsem E, Labianca R, Bodoky G, Barone C, Aranda E, Nordlinger B, Topham C, Tabernero J, Andre T, Sobrero AF, Mini E, Greil R, Di Costanzo F, Collette L, Cisar L, Zhang X, Khayat D, Bokemeyer C, Roth $\mathrm{AD}$, Cunningham D (2009) Randomized phase III trial comparing biweekly infusional fluorouracil/leucovorin alone or with irinotecan in the adjuvant treatment of stage III colon cancer: PETACC-3. J Clin Oncol 27: 3117-3125.

Viguier J, Boige V, Miquel C, Pocard M, Giraudeau B, Sabourin JC, Ducreux M, Sarasin A, Praz F (2005) ERCC1 codon 118 polymorphism is a predictive factor for the tumor response to oxaliplatin/5-fluorouracil combination chemotherapy in patients with advanced colorectal cancer. Clin Cancer Res 11: 6212-6217.

Watanabe Y, Koi M, Hemmi H, Hoshai H, Noda K (2001) A change in microsatellite instability caused by cisplatin-based chemotherapy of ovarian cancer. Br J Cancer 85: 1064-1069.

Zaanan A, Cuilliere-Dartigues P, Guilloux A, Parc Y, Louvet C, de Gramont A, Tiret E, Dumont S, Gayet B, Validire P, Flejou JF, Duval A, Praz F (2010) Impact of p53 expression and microsatellite instability on stage III colon cancer disease-free survival in patients treated by 5 -fluorouracil and leucovorin with or without oxaliplatin. Ann Oncol 21: 772-780.

Zaanan A, Flejou JF, Emile JF, Des GG, Cuilliere-Dartigues P, Malka D, Lecaille C, Validire P, Louvet C, Rougier P, de Gramont A, Bonnetain F, Praz F, Taieb J (2011) Defective mismatch repair status as a prognostic biomarker of disease-free survival in stage III colon cancer patients treated with adjuvant FOLFOX chemotherapy. Clin Cancer Res 17: 7470-7478.

This work is published under the standard license to publish agreement. After 12 months the work will become freely available and the license terms will switch to a Creative Commons AttributionNonCommercial-Share Alike 3.0 Unported License. 